\title{
Distribution and Restricted Vertical Movement of Nematodes in a Heavy Clay Soil
}

\author{
Oliver Knox ${ }^{1, *} \mathbb{C}$, Katherine Polain ${ }^{1} \mathbb{D}$, Elijha Fortescue ${ }^{1}$ and Bryan Griffiths ${ }^{2}$ \\ 1 School of Environmental and Rural Science, University of New England, Armidale 2351, NSW, Australia; \\ kpolain2@une.edu.au (K.P.); elijhafortescue@gmail.com (E.F.) \\ 2 Scotland's Rural College, King's Buildings, Edinburgh EH9 3JG, UK; beinnaghlo@gmail.com \\ * Correspondence: oknox@une.edu.au; Tel.: +61-2-67732946
}

Received: 24 December 2019; Accepted: 1 February 2020; Published: 4 February 2020

check for updates

\begin{abstract}
A large part of Australia's broad acre irrigation industry, which includes cotton, is farmed on heavy clay Vertosols. Recent changes in nematicide chemical availability, changes in rotations and the observation of the reniform nematode in central Queensland has highlighted that we need to improve our understanding of nematodes in these soils. We undertook preliminary investigations into distribution by depth under a cotton-cotton and cotton-maize rotation as well as vertical movement experiments in microcosms to better understand nematode distribution and movement in heavy clay soils. Analysis revealed that field populations decreased with soil sample depth, but there were also differences between rotations. In microcosm experiments, vertical movement of nematodes in these heavy clay soils was restricted, even in the presence of plant roots and moisture, both of which were hypothesised to improve nematode migration. The results imply that crop rotation currently remains a plausible option for nematode control, and that we still have a lot to learn about the ecology of nematode populations in Vertosols.
\end{abstract}

Keywords: Gossypium; Zea mays; vertisol; reniform

\section{Introduction}

In 2007, several experiments were undertaken within the Namoi valley cotton production area of New South Wales (NSW), Australia. These experiments were looking for interactions between genetically modified cotton and the soil biota [1], as well as the potential for an interaction between nematodes and the verticillium wilt [2,3], which is a production issue in the valley. At that time, there was no known nematode issue affecting Australian cotton production, although some potentially pathogenic nematodes were isolated [4,5], but these were in low numbers and possibly controlled by flood irrigation and the use of aldicarb [6].

Changes in funding and relocation of staff meant that continued monitoring was not possible; however, in 2014, a reversal in circumstance meant sampling, albeit to a limited extent, was recommenced. During the break in monitoring several changes occurred in the production system [7], with the removal of aldicarb and a shift to rotations that included maize being of note [8,9]. Additionally, Rotylenhus reniformis had been associated with yield losses around the Theodore area of central Queensland [10], which acted as a reminder of the importance of the Australian cotton industries 'come clean, go clean' policies [11]. The impact of reniform in Theodore also highlighted an industry requirement for more information on our nematode populations if we were to attempt to avoid the issues that were experienced in the USA. In the USA, reniform spread across almost half of the cotton fields of Alabama, Louisiana, and Mississippi in 50 years, reducing the yields by up to $20 \%[12,13]$. 
We asked two questions to address some of the current unknowns, with regard to the Australian cotton production system. One was whether the inclusion of maize into the cotton rotation could affect the distribution of nematodes in the soil profile? The second was, do nematodes have the potential to move up a soil profile under favourable conditions? We undertook a combination of field core assessments and glasshouse based recolonization studies to address these questions. The results of these experiments are presented and discussed.

\section{Materials and Methods}

\subsection{Soil Sites and Characteristics}

Vertical distribution of nematodes, with regard to rotation, was recovered from soils taken from field C1 at the Australian Cotton Research Institute (ACRI), Narrabri, NSW. The soil is an alkaline dark grey clay Vertosol (approximately $66 \%$ clay) with a known decreases in soil carbon down the profiles [14]. The rotation on the site has previously been explained in detail [15], and cores were taken to a depth of $1 \mathrm{~m}$ in January of 2017 with a portable coring rig [16] from within the cotton-cotton and cotton-maize rotations when both rotations were planted to cotton. Cores were returned to the University of New England (UNE), where they were divided into 0-15, 15-30, 30-50, 50-70, and $70-100 \mathrm{~cm}$ depths and nematodes were extracted using a passive recovery technique [17] prior to enumeration. Other field parameters, such as cropping history and planting dates, were gathered from field records at the time of sampling.

The soils gravimetric water content (GWC) was assessed by comparing the weight of a field fresh sample with the resultant weight after drying to a constant mass at $105^{\circ} \mathrm{C}$. The dry weight bulk density was calculated from the mass of the soils that were recovered from the core while assuming no compaction during sampling.

Two soils were used in the vertical movement experiments. The first, designated 'Kirby', was collected from UNE's Kirby farm and it was a sandy loam (grey Chromosol [18]); 73\% sand, $12 \%$ silt, and $14 \%$ clay with a $\mathrm{pH}_{\mathrm{H} 2 \mathrm{O}}$ ( 1 to 5 in water) of 5.4. The second soil, 'Cotton', was collected from a cotton property near Moree, NSW and it was a clay soil (black Vertosol [18]); $9 \%$ sand, $16 \%$ silt, and $74 \%$ clay with a $\mathrm{pH}_{\mathrm{H} 2 \mathrm{O}}$ of 8.2 .

\subsection{Soil Sterilization for Vertical Movement}

Soil was autoclaved in $1 \mathrm{~kg}$ amounts at $20 \%$ GWC in open bags for one hour at $121{ }^{\circ} \mathrm{C}$, at 1.5 bar and with the process repeated three times, with a $24 \mathrm{~h}$ break between the commencements of each autoclave cycle. Upon the completion of the sterilisation process, the autoclaved aliquots were combined into a sterile polypropylene bag and then left for two weeks in an open aseptic environment. After this time, three samples were taken from the soil and screened for nematode presence using passive extraction.

\subsection{Microcosm Design}

The microcosms were made from an unplasticised polyvinyl chloride (uPVC) pipe with an internal diameter of $50 \mathrm{~mm}$. The pipe was cut into $40 \mathrm{~cm}$ lengths, which were then cut longitudinally to allow for the microcosm to be split lengthwise to facilitate soil recovery. The bottom of the microcosm was held together and sealed with a $50 \mathrm{~mm}$ uPVC end cap and the top of the tube with a $50 \mathrm{~mm}$ uPVC pipe to pipe joining collar. The cut edges of the pipe were sealed with tape to prevent water loss and splitting under expansion of the soil. Under experimental conditions, the microcosms were supported in plastic crates, which carried up to 16 microcosms.

\subsection{Microcosm Packing}

The microcosms were packed, so that sterile and non-sterile soil was represented in all combinations within the experiments as either a top $(0-15 \mathrm{~cm})$ or bottom $(15-30 \mathrm{~cm})$ treatment. This meant that there was; Kirby top: Kirby bottom, Kirby sterile top: Kirby bottom, Kirby top: Kirby sterile bottom, 
and Kirby sterile top: Kirby sterile bottom with the same combinations for the Cotton soil. The soils were packed to generate a dry bulk density of $1.4 \mathrm{~g} / \mathrm{cm}^{3}$, which was achieved by weighing the required mass of soil for each half of the microcosm and adding one-third of the mass at a time before tamping the tube five times on the bench to get the required compaction. An internal $15 \mathrm{~cm}$ mark was present in each tube to assist with packing to the desired bulk density. After either the bottom or the tops of the tubes were packed water was added to the presenting surface to raise the gravimetric water content of the soil to $20 \%$.

\subsection{Planting and Watering}

Into the planted microcosms two seeds of wheat, variety Gregory, were planted to a depth of $1 \mathrm{~cm}$ and then the tops of all the microcosms were overlaid with $20 \mathrm{~mL}$ of $4 \mathrm{~mm}$ polypropylene beads to reduce evaporation. The initial starting weight of each established microcosm was taken and the GWC maintained by weight every Monday, Wednesday, and Friday of the experiment duration with the addition of variable amounts of rainwater to within $0.25 \mathrm{~g}$ of starting weight.

In a second experiment, a flood irrigation for half of the planted and unplanted microcosms was conducted two weeks after establishment by adding $50 \mathrm{~mL}$ of rain water to each of the identified microcosms. This was calculated as being sufficient water to raise the GWC to $35 \%$, which had been established as being equivalent to $-10 \mathrm{kPa}$.

\subsection{Recovery and Nematode Counting}

The microcosms were destructively sampled four weeks (28 days) after sowing wheat. The above ground plant height was recorded and the plant shoot material excised. Fresh weight was determined and the samples were dried for $48 \mathrm{~h}$ at $80{ }^{\circ} \mathrm{C}$ to determine the dry weight. Plastic beads were recovered from the top of the microcosms and then the tape and top and bottom caps were removed. The microcosms were opened in a large tray and the depth of visible root growth recorded. Soil was then recovered from 5 to $10 \mathrm{~cm}$ and 20 to $25 \mathrm{~cm}$ depths. A proportion of this soil was recovered to an aluminium tray to determine the GWC and approximately $10 \mathrm{~g}$ was weighed into a $50 \mathrm{~mL}$ centrifuge tube for nematode recovery [17].

\subsection{Results and Analysis}

Excel was used to tabulate results and interrogate data for correlation coefficients ( $\mathrm{r}$ ) generation. GenStat was used to undertake analysis of variance (ANOVA) of the measured variables, with Tukey's comparison test used to determine differences between multiple means with significance assumed to occur at the $p<0.05$ level. Outcomes were graphically presented.

\section{Results}

\subsection{Vertical Distribution}

The total free living nematode populations were observed to decrease with depth under both the cotton-cotton and cotton-maize rotations with the overall population decline fitting the equation $y=-0.0928 x^{3}+0.8549 x^{2}-2.7682 x+4.6508$, with a correlation of $r=0.99$. There was no significant difference between the rotations $(p=0.07)$, but there was a difference with depth $(p=0.001)$. An interaction between depth and rotation $(p=0.02)$ was observed with a larger nematode population in the cotton-cotton rotation between 30 to $70 \mathrm{~cm}$ than that recovered from under the cotton-maize rotation (Figure 1).

There was a good correlation between soil gravimetric water and nematode recovery from the cotton-maize rotation $(r=0.87)$, but not for cotton-cotton $(r=0.28)$. Both of the systems had good correlation between soil bulk density and the average number of nematodes $(r=0.80$ and 0.84$)$, with nematode abundance following a negative exponential curve as the bulk density increased. 


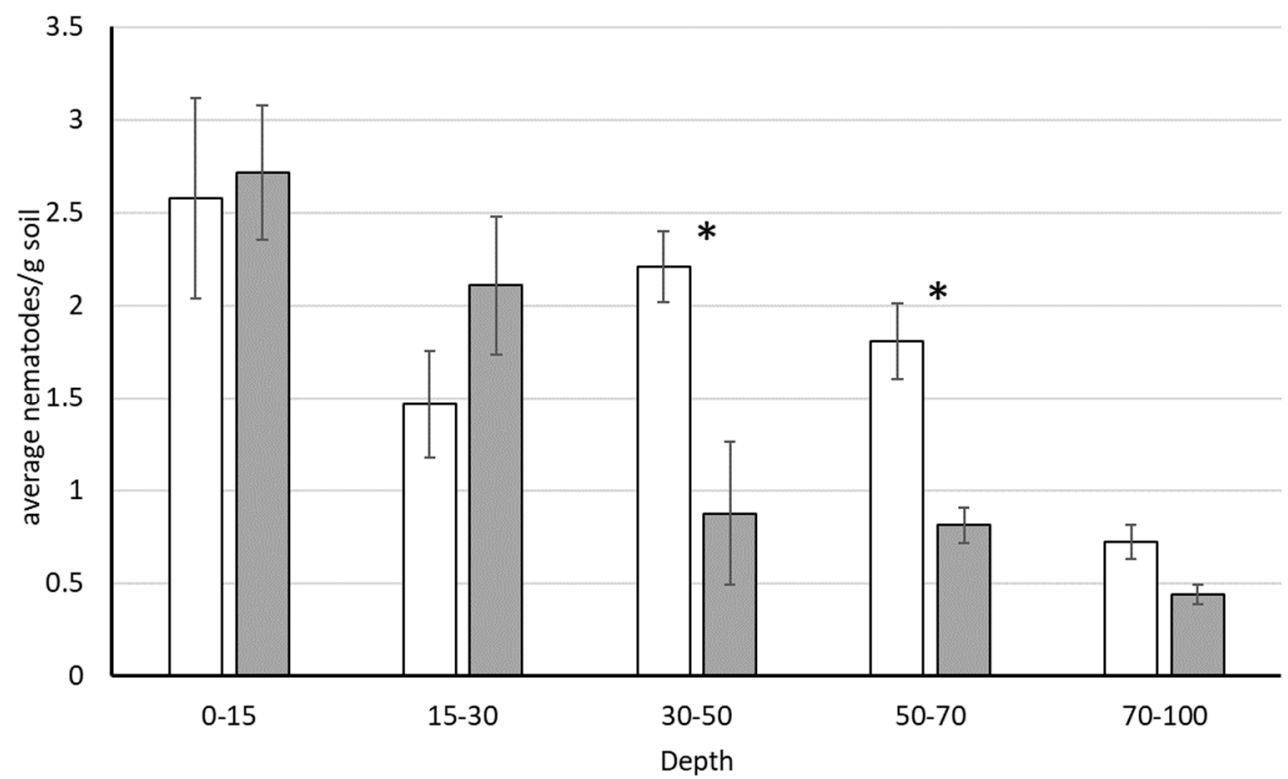

Figure 1. The mean free living nematodes per gram of soil recovered from a Vertosol supporting a cotton-cotton (white) and cotton-maize (grey) rotation to varying depths. Error bars represent the standard error of the means $(n=3)$ and the asterisks $\left(^{*}\right)$ indicate a significant difference between rotation and depth $(p=0.02)$.

\subsection{Vertical Movement}

The initial nematode populations were enumerated at 6.1 and 9.8 nematodes/g for the Kirby and Cotton soils, respectively. Examination of the soils, post sterilisation recovered no live nematodes in the Kirby soil, but the Cotton soil had 1.1 nematode/g (11\% of the original nematode population) still alive after three rounds of autoclaving.

In both microcosm experiments, the wheat roots reached the bottom of the columns in the Kirby soil $(30 \mathrm{~cm})$, but only managed an average depth of $20.6 \mathrm{~cm}$ in the Cotton soil. Despite this, the wheat biomass was significantly higher $(p<0.001)$ in the Cotton soil than the Kirby soil, with means of 0.3 and $0.1 \mathrm{~g}$, respectively.

In the first microcosm experiment, there was no significant difference in the nematode recovery between the Kirby and Cotton soils $(p=0.32)$, the top and bottom of the microcosms $(p=0.33)$, and whether wheat was planted or not $(p=0.11)$. Despite not being significant, nematode recovery, being expressed as a ratio of the control, implied movement up into sterile Kirby soil in both the presence and absence of wheat (Figure 2a). The average ratio of nematodes in sterile Cotton soil did not get above 1 in upper sterile Cotton soil, which implied a lack of upward movement (Figure 2a). In the bottom of the microcosms, there was a trend for increased nematode recovery in both sterile Kirby and Cotton soils, but only when wheat was planted (Figure 2a), despite the maintained 20\% gravimetric water content.

In the second microcosm experiment, imposing flood irrigation on the Cotton soil significantly increased the number of recovered nematodes $(p=0.07)$, with 2.7 as compared to 1.63 nematodes $/ \mathrm{g}$ for irrigated and GWC maintained soil, respectively. There was no significant difference in nematode recovery from either top or bottom of the microcosm $(p=0.39)$. Planting wheat had no significant effect on nematode recovery $(p=0.41)$, although the nematode recovery ratio increased above 1 for both irrigation treatments in the absence of planted wheat (Figure 2b). 
a

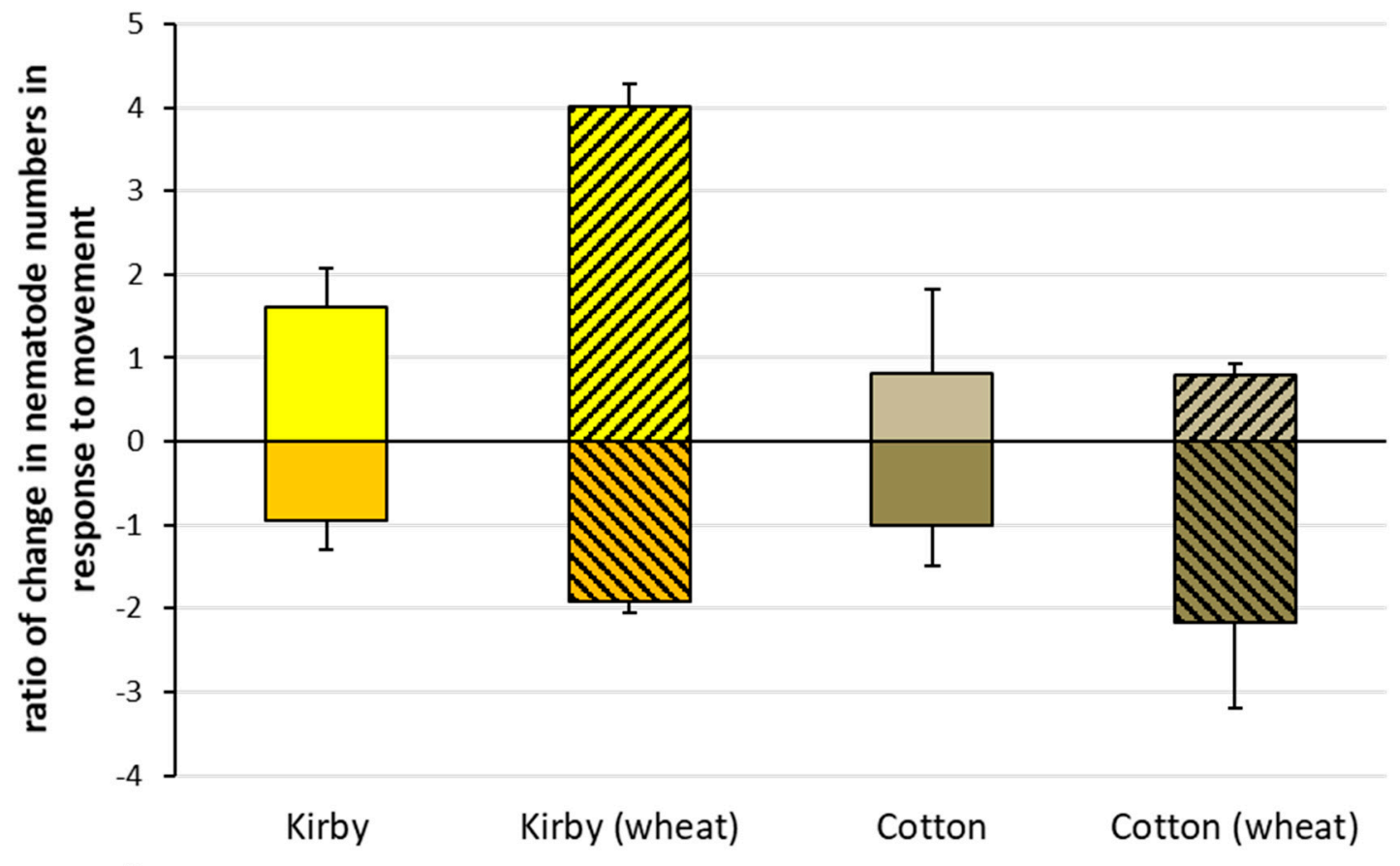

b

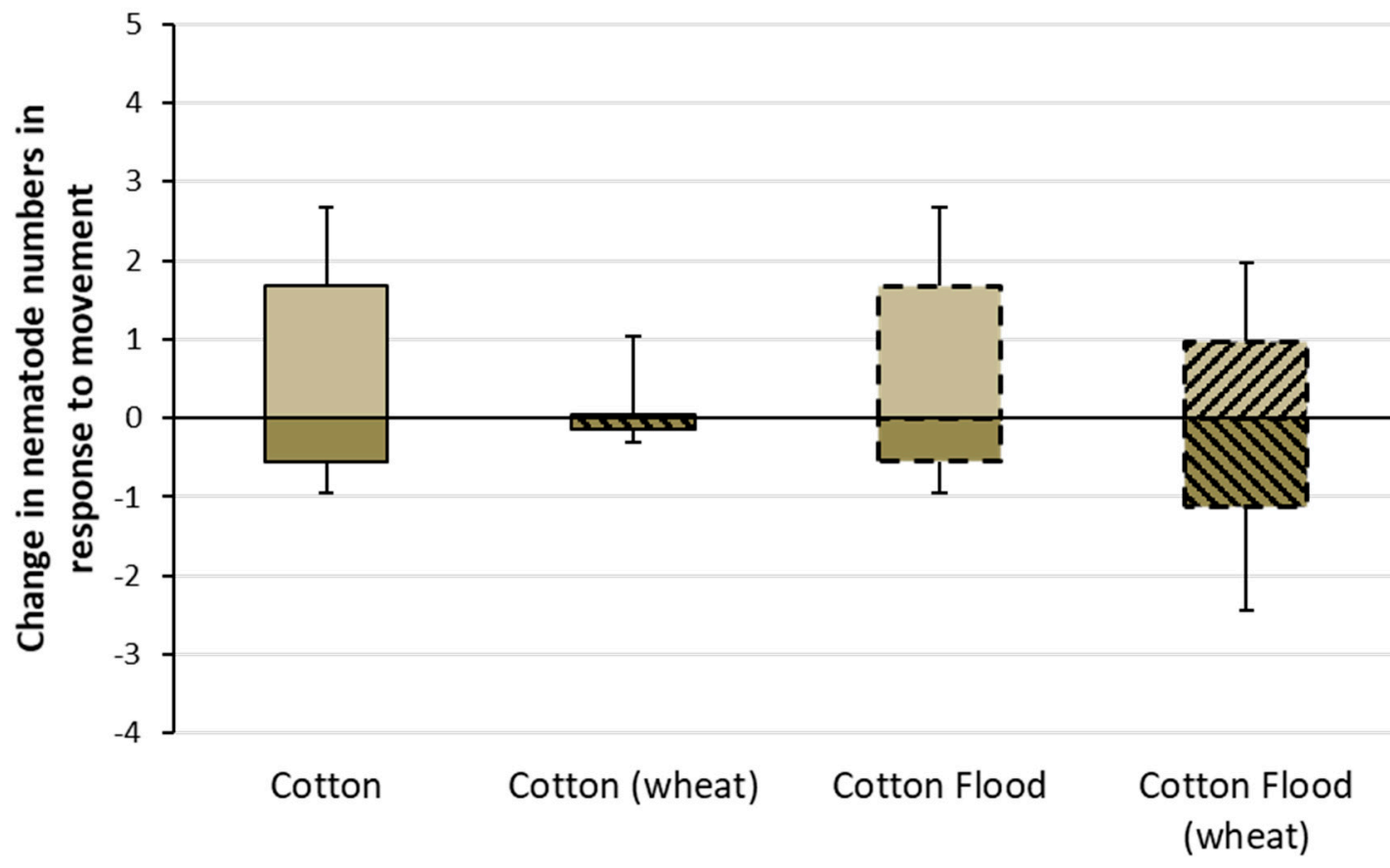

Figure 2. The ratio of nematodes recovered from sterilised soil situated either above or below non-sterile soil, compared to those recovered from a completely sterile treatment. A ratio of more than 1 (for upward movement, lighter shades) and -1 (for downward movement, darker shades) indicates an increase over the control. Kirby (Yellow) and Cotton (Brown) indicate where soil was sourced with (a) looking at the impact of sowing wheat (diagonal black shading) on nematode recovery, while (b) is the analysis of the impact of a maintained versus flood irrigation treatment (black dashed border) only in the Cotton soils.

\section{Discussion}

Farming systems are prone to change and the Australian cotton production system is no exception. However, the focus of these changes are often on either crop productivity or chemical and physical properties of the soil [19], with less attention being given to the soil biology [1], despite the fact that most, if not all, of our production diseases and pests are biological. We attempted to address some 
simple questions relating to nematodes in these systems in the face of the first observations of reniform nematode causing problems in Australian cotton [10] and the loss of potential chemical controls [8].

Our initial focus was on whether nematode populations declined with depth and whether rotations could influence their distribution. Our results indicated that there was a decline with depth as well as differences between rotations. Given that we sampled at a time when both of the rotations were growing cotton, we believe it would be safe to assume that the dissimilarity in the recovered nematodes/g between 30 to $70 \mathrm{~cm}$ (Figure 1) occurred due to rotational difference. With cotton being a tap rooted eudicot and maize a fibrous rooted monocot, a probable driver for changes in the nematode numbers between these depths is rooting patterns $[20,21]$ in combination with these roots persisting post-harvest [22]. Root exudation and decomposition both have the potential to alter the soil microbiology [23], which, in turn, would directly influence both the nematode community composition and size [24]. Differences in the field management that are associated with the different rotational crops, such as fertilizer regimes, cultivation, and stubble management, could also be altering the soil microbial community and in turn the nematodes [25]. In keeping with this, cotton and maize roots are known to differentially alter the soils' abiotic properties [9], thus potentially altering the nematode population densities, which was supported with the observed correlations between nematode numbers, soil moisture, and bulk density. What a change is abundance does not address is whether it is also associated with a change in the population's trophic groups? Unfortunately, limitations on the volume of soil in our microcosms, our inability to remove all of the nematodes from the Cotton soil with autoclaving and the recoveries of only one to two nematodes/g from the recolonized soil, there was insufficient numbers to confirm this. However, with known pathogenic nematodes in these soils and a potential industry threat identified elsewhere, the difference in nematode abundance in soil from under the different rotations adds support for rotational crops remaining one of the few strategies available at present for nematode control in Australian cotton system [26,27].

Having observed a difference between the rotations, we postulated whether there was potential for nematodes to move vertically within these soils. Vertical nematode movement has been previously reported, notably for several plant parasitic nematodes that recolinise and recover from populations that reside deeper in the soil after crop protection control measures, such as nematicide application, have been implemented [28,29]. However, this work was undertaken on lighter soils than the Vertosol soil being investigated here [29]. Water is known to play a key role in both nematode movement and shaping community structure [30-32], and so we initially kept our soils at a moisture level that should have facilitated nematode movement [30]. However, in our limited and short term experiments, nematode movement either up or down in a heavy clay Vertosol appeared to be restrictive (Figure 2). In addition, we included the planting of wheat as a treatment factor, while assuming that the presence of growing roots might encourage nematode movement [33], but we observed no significant movement in response to plant roots (Figure 2). While surprising, it has been previously reported that the vertical distribution of roots does not always correlate to nematode movement or abundance [34]. While our microcosm experiments imply limited nematode movement and recolonisation potential in Vertosols, there are a number of caveats to consider prior to deriving any generalisations regarding nematode movements in these heavy clay soils. Firstly, our system was only run for four weeks, a relatively short period of time in a cropping cycle, we had limited replication and our Vertosol columns were not exposed to repeated flooding and drying cycles, as experienced under field conditions, but kept constantly moist. Finally, we did not work on the soils containing the reniform nematode due to quarantine concerns, but, given the potential for nematodes to behave differently, could not rule out the potential for R. reniformis to recolonise Vertosols from depth after flooding [10,28].

Accordingly, whilst these studies were preliminary, it is apparent that we still have much to learn about the diversity, potential threats, activity and importance of nematodes in Australian Vertosols, which themselves are challenging to work with. Within these heavy clay soils, the potential to use crop selection as a control strategy remains $[26,27]$. In the face of a reduction in available chemical controls [8], this strategy may continue to be one of the few mitigation options other than preventing 
nematode movement from infected fields [10] in the first place by maintaining 'come clean, go clean' practices [11].

Author Contributions: O.K. and B.G. undertook sampling, analysis and manuscript preparation. K.P. assisted with soils analysis and E.F. assisted with soil sampling and nematode enumeration. All authors have read and agreed to the published version of the manuscript.

Funding: This work was made possible with funding from the CRDC under UNE1403 and UNE2001. The University of New England (UNE) contributed via the GRASS programme, which supported Elijha, Katherine's PhD and in-kind and cash to UNE1403 and UNE2001.

Acknowledgments: Access to the trial sites and farms is gratefully acknowledged as is glasshouse support from Mick Faint at UNE.

Conflicts of Interest: The authors declare no conflict of interest.

\section{References}

1. Knox, O.G.G.; Gupta, V.V.S.R.; Lardner, R. Field evaluation of the effects of cotton variety and GM status on rhizosphere microbial diversity and function in Australian soils. Soil Res. 2014, 52, 203-215. [CrossRef]

2. Francl, L.J.; Wheeler, T.A. Interaction of Plant-Parasitic Nematodes with Wilt-Inducing Fungi. In Nematode Interactions; Khan, M.W., Ed.; Springer: Dortrecht, Germany, 1993; pp. 79-103.

3. Katsantonis, D.; Hillocks, R.J.; Gowen, S. Comparative Effect of Root-Knot Nematode on Severity of Verticillium and Fusarium Wilt in Cotton. Phytoparasitica 2003, 31, 154-162. [CrossRef]

4. Knox, O.G.G.; Anderson, C.M.T.; Allen, S.J.; Nehl, D.B. Helicotylenchus Dihystera in Australian Cotton Roots. Australas. Plant Pathol. 2006, 35, 287-288. [CrossRef]

5. Knox, O.G.G.; Anderson, C.M.T.; Nehl, D.B.; Gupta, V.V.S.R. Observation of Tylenchorhynchus ewingi in association with cotton soils in Australia. Australas. Plant Dis. Notes 2006, 1, 47-48. [CrossRef]

6. Cox, C. Aldicarb. J. Pestic. Reform 1992, 12, 4.

7. Braunack, M.V. Cotton farming systems in Australia: Factors contributing to changed yield and fibre quality. Crop Pasture Sci. 2013, 64, 834-844. [CrossRef]

8. Erickson, B. Pesticides: Bayer Cropscience, EPA Agree to Phase Out Use of Aldicarb. Chem. Eng. News 2010, 88, 1. [CrossRef]

9. Hulugalle, N.R.; McCorkell, B.; Heimoana, V.F.; Finlay, L.A. Soil properties under cotton-corn rotations in Australian cotton farms. J. Cotton Sci. 2016, 20, 294-298.

10. Bauer, B.; Smith, L.; Scheikowski, L.; Lehane, J.; Cobon, J.; O'Neill, W. Reniform Nematode Surveys in Central Queensland Cotton. In Proceedings of the 17th Australian Cotton Conference, Gold Coast, Australia, 4-6 August 2020; pp. 1-3.

11. Maas, S. Come Clean Go Clean. Cottoninfo Fact Sheet 2014, 2. Available online: http://www.insidecotton.com/ xmlui/handle/1/1015 (accessed on 4 February 2020).

12. Gazaway, W.S.; Mclean, K.S. A survey of plant-parasitic nematodes associated with cotton in Alabama. J. Cotton Sci. 2003, 7, 1-7.

13. Monfort, W.S.; Kirkpatrick, T.L.; Mauromoustakos, A. Spread of Rotylenchulus reniformis in an Arkansas Cotton Field Over a Four-Year Period. J. Nematol. 2008, 40, 161-166.

14. Polain, K.; Guppy, C.; Knox, O.; Lisle, L.; Wilson, B.; Osanai, Y.; Siebers, N. Determination of Agricultural Impact on Soil Microbial Activity Using $818 \mathrm{OP} \mathrm{HCl}$ and Respiration Experiments. ACS Earth Space Chem. 2018, 2, 683-691. [CrossRef]

15. Nachimuthu, G.; Hulugalle, N.R.; Watkins, M.D.; Finlay, L.A.; McCorkell, B. Irrigation induced surface carbon flow in a Vertisol under furrow irrigated cotton cropping systems. Soil Tillage Res. 2018, 183, 8-18. [CrossRef]

16. Polain, K.; Joice, G.; Jones, D.; Pereg, L.; Nachimuthu, G.; Knox, O.G.G. Coring lubricants can increase soil microbial activity in Vertisols. J. Microbiol. Methods 2019, 165, 105695. [CrossRef] [PubMed]

17. Knox, O.G.G.; Griffiths, B.S. Refinement of Passive Nematode Recovery from Cotton Growing High Clay Content Australian Vertisols. Commun. Soil Sci. Plant Anal. 2017, 48, 316-325. [CrossRef]

18. Isbell, R.F. The Australian Soil Classification; CSIRO Publishing: Collingwood, Australia, 1996.

19. Hulugalle, N.R.; Nehl, D.B.; Weaver, T.B. Soil properties, and cotton growth, yield and fibre quality in three cotton-based cropping systems. Soil Tillage Res. 2004, 75, 131-141. [CrossRef] 
20. Hulugalle, N.R.; Broughton, K.J.; Tan, D.K.Y. Root growth of irrigated summer crops in cotton-based farming systems sown in Vertosols of northern New South Wales. Crop Pasture Sci. 2015, 66, 158-167. [CrossRef]

21. Luelf, N.; Tan, D.; Hulugalle, N.; Knox, O.; Weaver, T.; Field, D. Root turnover and microbial activity in cotton farming systems. In Proceedings of the 13th Australian Agronomy Conference, Perth, Australia, 10-14 September 2006.

22. Machinet, G.E.; Bertrand, I.; Chabbert, B.; Watteau, F.; Villemin, G.; Recous, S. Soil biodegradation of maize root residues: Interaction between chemical characteristics and the presence of colonizing micro-organisms. Soil Biol. Biochem. 2009, 41, 1253-1261. [CrossRef]

23. Broeckling, C.D.; Broz, A.K.; Bergelson, J.; Manter, D.K.; Vivanco, J.M. Root exudates regulate soil fungal community composition and diversity. Appl. Environ. Microbiol. 2008, 74, 738-744. [CrossRef]

24. Ferris, H.; Griffiths, B.S.; Porazinska, D.L.; Powers, T.O.; Wang, K.-H.; Tenuta, M. Reflections on Plant and Soil Nematode Ecology: Past, Present and Future. J. Nematol. 2012, 44, 115-126.

25. Griffiths, B.S.; Philippot, L. Insights into the resistance and resilience of the soil microbial community. FEMS Microbiol. Rev. 2013, 37, 112-129. [CrossRef]

26. Roberts, P.A. Current status of the availability, development, and use of host plant resistance to nematodes. J. Nematol. 1992, 24, 213. [PubMed]

27. Stirling, G.R. Biological control of plant-parasitic nematodes. In Diseases of Nematodes; Poinar, G.O., Ed.; CRC Press: Boca Raton, FL, USA, 2018; pp. 103-150.

28. Lee, H.K.; Lawrence, G.W.; DuBien, J.L.; Lawrence, K.S. Seasonal variation and cotton-corn rotation in the spatial distribution of Rotylenchulus reniformis in Mississippi cotton soils. Nematropica 2015, 45, 72-81.

29. Pinkerton, J.N.; Mojtahedi, H.; Santo, G.S.; O’Bannon, J.H. Vertical Migration of Meloidogyne chitwoodi and M. hapla under Controlled Temperature. J. Nematol. 1987, 19, 152-157. [PubMed]

30. Knox, O.G.G.; Killham, K.; Artz, R.R.E.; Mullins, C.; Wilson, M. Effect of Nematodes on Rhizosphere Colonization by Seed-Applied Bacteria. Appl. Environ. Microbiol. 2004, 70, 4666-4671. [CrossRef] [PubMed]

31. Liu, M.; Chen, X.; Qin, J.; Wang, D.; Griffiths, B.; Hu, F. A sequential extraction procedure reveals that water management affects soil nematode communities in paddy fields. Appl. Soil Ecol. 2008, 40, 250-259. [CrossRef]

32. Wallace, H.R. The Dynamics of Nematode Movement. Annu. Rev. Phytopathol. 1968, 6, 91-114. [CrossRef]

33. Standing, D.; Knox, O.G.G.; Mullins, C.E.; Killham, K.K.; Wilson, M.J. Influence of Nematodes on Resource Utilization by Bacteria; an in Vitro Study. Microb. Ecol. 2006, 52, 444-450. [CrossRef]

34. Forge, T.A.; DeYoung, R.; Vrain, T.C. Temporal changes in the vertical distribution of Pratylenchus penetrans under raspberry. J. Nematol. 1998, 30, 179. 